\title{
COMPLEXIDADE LINGUÍSTICA E AQUISIÇÃO DE L2: PANORAMA TEÓRICO
}

\section{LANGUAGE COMPLEXITY AND L2 ACQUISITION: A THEORETICAL VIEW}

\author{
Ednei de Souza Leal ${ }^{1}$ | Lattes | edsleal79@gmail.com \\ Universidade Federal de São Carlos | CAPES
}

\begin{abstract}
Resumo: Este artigo tem como objetivo apresentar um parâmetro utilizado para se medir complexidade linguística, parâmetro este advindo dos estudos da Linguística Aplicada. Antes, porém, apresentaremos brevemente os rumos dos estudos da Complexidade Linguística e por que a diferença de complexidade entre as línguas se tornou um tabu. Este trabalho se faz pertinente porque há pouca ou mesmo nenhuma literatura a respeito no Brasil ou mesmo em Língua Portuguesa. Por outro lado, queremos fazer um justo apontamento da contribuição da Linguística Aplicada aos apontamentos sobre Complexidade Linguística. Dito de outra forma, o que faremos aqui, via de regra, é apontar uma possibilidade de se medir complexidade que há muito já existe, mas que parece inatingível à Linguística Teórica.
\end{abstract}

Palavras-chave: Aquisição de Segunda Língua (SLA). Complexidade Linguística. Complexidade. Precisão e Fluência (CAF). Filosofia da Linguística.

\begin{abstract}
This article aims to present a parameter for the analysis of linguistics, with the studies of Applied Linguistics. Firstly, however, we present the directions of the Studies of Language Complexity, and why the difference in the degree o complexity between Languages has become a taboo. This work is relevant because there is nothing or no other documentation on the same subject in Brazil or even in the Portuguese Language, by means of a list referring to the Language Complexity. Put in another way, what is done here, at least, is a possibility to measure such a degree that, though existing long ago, seems unattainable to Theoretical Linguistics.
\end{abstract}

Key-words: Second Language Acquisition (SLA). Language Complexity. Complejidad. Precisión y Fluidez (CAF). Philosophy of Linguistics.

\footnotetext{
${ }^{1}$ Doutorando do Programa de Pós-Graduação em Linguística da Universidade Federal do São Carlos (PPGL-UFSCar). Bolsista CAPES-2016.
} 


\section{Introdução}

Já é consenso entre linguistas que estudam Complexidade Linguística que há uma íntima relação entre a complexidade das línguas e sua idade, ou como querem Dahl (2004) e McWhorter (2007), sua maturação. Nesse sentido, línguas jovens como pidgins, crioulos e outras originárias a partir de contato tendem a ser menos complexas em dados níveis, seja sintático ou morfológico, por exemplo, justamente porque, sendo recentes essas línguas, tiverem menos tempo de maturação. Dessa forma, pode-se também supor que falantes de uma língua estrangeira produzem uma espécie de "língua simplificada". Então, seria conveniente aos estudiosos da chamada Complexidade Linguística investigarem parâmetros também utilizados nos estudos de Aquisição de Segunda Língua (SLA, do inglês Second Language Acquisition).

Procuraremos mostrar neste artigo quais são os parâmetros linguísticos da SLA utilizados nos estudos da Complexidade Linguística e suas consequentes contribuições para esta. Ou seja, mostrar os parâmetros utilizados nos estudos de SLA que também são aproveitáveis para os estudos da Complexidade Linguística.

CAF (da sigla inglesa, Complexity, Accuracy, Fluence, ou seja: Complexidade, Precisão e Fluência) é, na verdade, um método utilizado na SLA para avaliar o nível de aquisição de um falante de Segunda Língua (L2). Dessa forma, nosso foco, aqui, são as pesquisas de Aquisição de L2 associadas aos estudos sobre Complexidade Linguística.

Para tal, procuraremos antes definir alguns termos basilares, como, por exemplo, o que se entende por Complexidade Linguística na literatura corrente, sua história e, consequentemente, o porquê de o termo tornar-se um tabu nos estudos linguísticos até o final do século XX. Obviamente só conseguiremos atingir tais objetivos ante uma reflexão crítica acerca dos estudos sobre Complexidade Linguística, a princípio do ponto de vista histórico (ROBINS, 1979), e criticamente, do ponto de vista da Filosofia da Ciência (BORGES NETO, 2002).

\section{Complexidade: um tabu linguístico - breve histórico}

Possivelmente, desde a Antiguidade, tanto falantes quanto especialistas notam diferentes graus de complexidade entre as línguas. No século XIX, sob a influência da filosofia romântico-nacionalista, a questão foi fortemente delineada, no entanto, sem muito apreço teórico, sobretudo no que dizia respeito a fatores realmente linguísticos. A preocupação, num primeiro momento, era a de comparar as línguas para que se pudesse afirmar a posição supostamente superior de um país/nação ante outro. Assim, com vistas aos 
estudos posteriores, pouco ou nada se pode levar em consideração ao domínio da complexidade linguística.

Afora estudos sistemáticos de Wilhelm von Humboldt (ROBINS, 1979) que, mesmo dentro do paradigma romântico-nacionalista, consegue vislumbrar diferenças estruturais significativas entre línguas de famílias bastante diversas, como o hebraico e o alemão, por exemplo, quase nenhum estudo sobre a linguagem até a primeira metade do século XIX contempla, de maneira satisfatória, alguma nota acerca da natureza complexa da linguagem humana.

Mais tarde, com o avanço do paradigma histórico-comparativo, a questão da Complexidade se distancia ainda mais das preocupações dos estudiosos sobre a língua. Novamente, não se fazia relevante à complexidade, isso porque o que se queria provar era, de certo modo, a equivalência ou a continuidade, sobretudo sonora, entre as línguas. Ao se comparar o Sânscrito, antiga língua sagrada da Índia, com as línguas europeias, nota-se o parentesco entre elas e, portanto, há aí uma equiparação “justa” entre línguas. Em especial, há equiparação entre línguas que antes eram consideradas inferiores. Nesse sentido, a estreia de um método científico aos estudos da linguagem serve para desfazer um "mal-entendido" histórico e social bastante presente na época: o de que poderiam existir línguas inferiores.

Já no século XX, sobretudo depois de estabelecida a chamada Linguística Estruturalista, a questão da Complexidade Linguística perde quase que completamente seu sentido. Fortemente influenciada pela Antropologia de Franz Boas (apud ROBINS, 1979), o chamado Estruturalismo norte-americano, mais por questões éticas e menos por questões técnico-metodológicas, propõe que todas as línguas do mundo são equivalentes com relação à sua complexidade. Dito de outra forma: equipara-se a complexidade entre as línguas, sob influência das descobertas sociais, para que não se abra discussões inoportunas, tais como a capacidade dos falantes. Isso se deu, muito possivelmente, porque esses estudiosos se ocupavam em descrever línguas da América do Norte, que, como se sabe, possuem estruturas completamente diferentes daquelas estudadas exaustivamente na Europa, constatando, assim, a complexidade dessas línguas ao descrevê-las (ROBINS, 1979).

O capítulo final entre Estruturalismo e Complexidade talvez se dê com o linguista norte-americano pós-bloomfiediano Charles Hockett. Em sua obra A Course in Modern Linguistic, de 1958, esse autor define a questão de Complexidade Linguística, reafirmando noções inspiradas na Antropologia de que todas as línguas naturais seriam equivalen- 
tes no tocante à sua complexidade. Tal ponto de vista explicaria suas diferenças estruturais apenas com uma espécie de "lei das compensações". Por exemplo, no que tange a diferenças entre o inglês e a maior parte das línguas românicas no tocante à morfologia verbal seria a compensação do sistema pronominal mais complexo que a língua inglesa apresenta, fazendo, assim, um justo equilíbrio ao que lhe falta na morfologia verbal. $\mathrm{Na}$ verdade, Hockett (1958 apud MIESTAMO, SINNEMÄKI, KARLSSON, 2008) dedica-se a provar que há equivalência de complexidade entre todas as línguas naturais. Embora válido, seu esforço não condiz com testes empíricos verificáveis, o que torna a equidade de complexidade entre as línguas um tabu que, por muitos anos, evitou-se ser discutido no meio acadêmico.

Na segunda metade do século XX, com a ascensão da Gramática Gerativa Transformacional como paradigma nos estudos linguísticos, a preocupação de teor biológico mais do que social agora é o de encontrar "princípios" comuns em todas as línguas do mundo. Novamente, o que se vê é uma equiparação das línguas do mundo. Não há uma discussão sobre os diferentes graus de complexidade das línguas, ao menos alguma discussão teoricamente relevante a esse respeito.

Embora se suponha que tratar de complexidade equivale a observar a estrutura formal da língua, ou seja, seu aparato gramatical, foi no âmbito da Sociolinguística que primeiramente se falou da diferença de complexidade entre as línguas. Segundo Newmeyer e Preston (2014), foi em David Trudgill, com sua obra On Dialect: Social and Geographical Perspectives de 1983 (apud SAMPSON; GIL; TRUDGILL, 2009), que, pela primeira vez, encontramos a hipótese de que poderia haver diferentes graus de complexidade entre as línguas do mundo. No entanto, as discussões pormenorizadas sobre o assunto viriam a surgir apenas no final do século XX.

Na próxima seção detalharemos melhor os estudos sobre a complexidade das línguas, bem como suas definições e parâmetros.

\section{Complexidade: definições e parâmetros de trabalho}

Para procurarmos definir o conceito moderno do que seja Complexidade Linguística, nos utilizaremos de algumas obras sobre o assunto, tais como Miestamo, Sinnemäki e Karlsson (2008), Kusters (2003), mas, sobretudo Dahl (2004).

Em estudos anteriores, a questão da Complexidade Linguística sempre esteve atrelada à valoração da língua, mas obviamente não se trata disso: uma língua que apresente um sistema de caso reduzido ou mesmo inexistente não é necessariamente mais simples 
do que uma língua rica em caso, como o alemão em comparação ao português, por exemplo. Supõe-se, assim, - veja-se o caso do latim e suas línguas herdeiras - que haveria, na perda de um paradigma (os casos, por exemplo), uma espécie de ganho por outro lado na complexidade (a ordem rígida na sintaxe), pois se atesta que não são línguas fáceis, ou seja, não há línguas sem complexidade. ${ }^{2}$

Uma das primeiras discussões pertinentes que podemos levantar no campo da Complexidade Linguística é se se trata de um campo de estudos ou de uma noção inerente à língua. Para Kusters (2003), a Complexidade Linguística pode ser definida inicialmente de duas maneiras: (i) é uma característica inerente a toda e qualquer língua natural, portanto, é passível de ser estudada; ou (ii) é definida como uma "ferramenta" capaz de contribuir com explicações de fenômenos linguísticos. O que queremos dizer com isso, e de acordo com Kusters (2003) e Miestamo, Sinnemäki e Karlsson (2008), é que a Complexidade Linguística ainda não está estabelecida como um campo de estudos coeso, tampouco como um programa de estudo sistemático sobre as línguas. Ainda assim, há mais de uma década, acontecem congressos especializados e muitas obras já foram editadas sobre o assunto.

Assim, embora não se caracterize epistemologicamente como programa de estudo, existe um número crescente de teóricos na área em questão que se dedicam ao problema. Problema, aliás, pouco delimitado e mesmo sem uma definição consolidada. Por isso, a nosso ver, é premente um trabalho crítico dos estudos sobre Complexidade Linguística, possivelmente um estudo nos parâmetros da Filosofia da Linguística, que é o que nos propomos a fazer aqui de modo bastante modesto.

Afora esses problemas, o termo em si, por ser amplo, gera bastante confusão, mesmo nos meios especializados. Coincidentemente, no final do século XX surgem Teorias da Complexidade advindas dos estudos biológicos. Ora, outros campos do conhecimento, a Linguística inclusive, tomam como ponto de partida tais estudos para explicar seus fenômenos particulares. Não cabe aqui diferenciarmos entre a Teoria da Complexidade adotada por certos ramos da Linguística, em especial a Linguística Aplicada, e o que estamos chamando aqui de estudos de Complexidade Linguística. Basta dizer que esses eclodem exclusivamente de estudos sobre a língua natural, enquanto as Teorias da Complexidade são adaptadas a realidades linguísticas.

\subsection{O que é Complexidade Linguística}

Há pelo menos dois pontos de vista divergentes com relação ao objeto observacional e mesmo acerca de como se enxergar o objeto teórico: o ponto de vista 'relati-

\footnotetext{
${ }^{2}$ Salvo os pidgins, dos quais falaremos adiante.
} 
vista', e o ponto de vista 'absoluto'. Desse modo, para linguistas como Miestamo (apud MIESTAMO; SINNEMÄKI; KARLSSON, 2008), o ponto de vista 'relativista' diz respeito a um conjunto de enunciados passivos de observações empíricas, portanto, passíveis de serem mensurados e, até explicados. Enquanto que Kusters (apud MIESTAMO; SINNEMÄKI; KARLSSON, 2008) entende que o ponto de vista 'relativo' seria melhor explicado como uma soma dos dados obtidos de uma porção absoluta do objeto. Dito de outra forma, diferentemente de Miestamo, Kusters acredita na possibilidade de medir complexidade linguística sob a ótica "absoluta” do objeto linguístico.

Segundo esses autores, Complexidade Absoluta diz respeito ao modo de ver ou mesmo de medir complexidade de uma língua em todo seu sistema. Assim, para medir ou enxergar a complexidade de uma língua, deve-se observar seu sistema por inteiro, e o que definiria sua complexidade, então, seria a quantidade de subsistemas atrelados a esse sistema "geral" que, de maneira abstrata, descreve a língua. Desse modo, é mais complexa uma língua que apresenta maior complexidade em seus subsistemas. Para os mesmos autores, Complexidade Relativa seria medir cada um desses subsistemas em separado, para daí se obter alguma resposta pertinente no tocante à complexidade de uma língua. Para Culicover (2013), no entanto, a Complexidade Absoluta é impossível de ser medida. Östen Dahl (2004), embora concorde com Miestamo (apud MIESTAMO; SINNEMÄKI; KARLSSON, 2008 e Kusters (apud MIESTAMO; SINNEMÄKI; KARLSSON, 2008), discorda da posição da Complexidade Absoluta. Para Dahl, a Complexidade Absoluta se resume em: quanto mais complexo é cada um dos subsistemas de uma língua, mais complexa ela é.

\subsection{Como Medir Complexidade Linguística}

Das propostas advindas dos estudos sobre Complexidade Linguística, surgem linguistas das mais diferentes áreas: desde a Sociolinguística (TRUDGILL, 1983 apud SAMPSOM; GIL; TRUDGILL, 2009) até a Gramática Gerativa (CULICOVER, 2013). Assim, há diferentes propostas de se medir a complexidade das línguas, embora nenhuma conclusiva. Isso quer dizer, grosso modo, que sequer há ainda um método conclusivo, mínimo que seja, para medir complexidade linguística. O que há de fato é a assunção geral de que diferentes línguas possuem diferentes graus de complexidade, ou mesmo que há línguas que possuem menos complexidade, como propõe Everett (apud MIESTAMO; SINNEMÄKI; KARLSSON, 2008) em seus estudos sobre o pirahã. Além disso, estudos significativos de McWorther (2007) apontam para a falta de complexidade em línguas de contato. 
Para Hawkins (2014), por exemplo, o fato de uma língua tornar-se mais complexa advém de fatores externos à língua: falta de contato entre línguas, fatores pragmáticos, dentre outros. Já para Culicover (2013), a observação atenta à Gramática dará a resposta sobre a Complexidade Linguística. Para esse linguista, a tensão entre Competência e Desempenho pressupõe duas forças que agem na gramática: (i) a pressão para reduzir a complexidade formal da gramática e (ii) a pressão para evitar a complexidade na aplicação da gramática a expressões linguísticas reais, isto é, a Complexidade de Processamento. Para fazer isso, segundo ele, é pertinente responder a duas questões: o que é gramática e como medir a complexidade desta gramática.

A dificuldade reside no fato de que nenhuma das duas respostas é conclusiva, isso porque há uma série de propostas em voga sobre o que constitui a gramática, e sobre o que constitui a complexidade, tanto a complexidade formal, quanto a complexidade de processamento. Assim, um primeiro caminho para se medir complexidade seria, em primeiro lugar, determinar o que seria a complexidade formal numa gramática e, posteriormente, o que seria a complexidade de processamento dessa mesma gramática.

Ao estudar diferentes variedades do quéchua, Kusters (2003) observou aspectos sobre a natureza verbal dessas variedades: um dos sistemas (o mais antigo) com o paradigma verbal pleno, e duas delas com o paradigma verbal mais simplificado, sendo uma delas, a qual foi utilizada como língua franca, um paradigma ainda mais simplificado. Após observações, Kusters concluiu que há três critérios conjugados que poderiam determinar diferentes graus de complexidade das variantes dessa língua:

(1) Critério de Economia, ou seja, o número de categorias expressas pelo verbo; assim, quanto menos paradigma um verbo apresentar, mais econômico ele é;

(2) Critério de Transparência: ao expressar, por exemplo, a pessoa num morfema, o verbo é mais transparente que aquele que não faz isso;

(3) Critério de Isomorfia: diz respeito à cristalização de certas palavras e expressões que a língua possui.

Posteriormente, o mesmo Kusters (apudMIESTAMO, SINNEMÄKI, KARLSSON, 2008 ) propõe um esquema mais robusto para medir Complexidade Linguística, o qual expomos aqui de maneira resumida. Segundo o linguista, tal metodologia poderia ser dividida em três assunções: 1) modos epistêmicos, 2) modos ontológicos, e 3) complexidade funcional. Os modos epistêmicos são divididos em: a) Complexidade Descritiva, que é a medida que deve ser fornecida para a descrição adequada de um dado sistema; b) Complexidade Gerativa, que é um conjunto de instruções que devem ser fornecidas para 
indicar a produção de um dado sistema; e c) Complexidade Computacional, que é a quantidade de tempo e esforço envolvidos na resolução de um problema que envolve medidas de complexidade linguística. Os modos ontológicos, por sua vez, são divididos em: a) Complexidade Composicional, que diz respeito ao uso dos fonemas e suas articulações para o bom funcionamento de um sistema linguístico; b) Complexidade Estrutural, que diz respeito às maneiras de como um sistema é utilizado, isso incluindo suas hierarquias léxico-semânticas. Já a chamada complexidade funcional pode ser dividida da seguinte forma: a) Variedade de Modos de Operação ou Tipos de Funcionamento, por exemplo, variedade de usos situacionais de expressões: variedade de estilos e situações de fala e diferenças relacionadas com os custos relativos à produção linguagem; b) Complexidade Cognitiva, que diz respeito às limitações neurológicas e anatômicas na produção da fala. Hawkins (2014) aposta em dados extralinguísticos para explicar os fenômenos da complexidade. Ainda assim, ele não perde de vista os fenômenos estruturais das línguas. No referido trabalho, ele mostra que línguas de ordem OV (objeto precedido de verbo, ou simplesmente Objeto, Verbo) são mais complexas que línguas de ordem VO (analogamente, Verbo, Objeto). Ao mesmo tempo, línguas de ordem OV são mais raras que línguas de ordem VO.

Em 2007, no Workshop on Complexity in Language: Developmental and Evolutionary Perspectives, Tao Gong \& Christophe Coupé (GONG; COUPÉ, 2011) expuseram uma proposta de medir Complexidade Linguística baseada nas noções do pesquisador de inteligência artificial Luc Steels (apud GONG E COUPÉ, 2011). Propõem eles, então, cinco procedimentos, a saber: (i) descrever uma estrutura linguística complexa; (ii) identificar suas funções; (iii) reconstruir o processamento e os mecanismos de aquisição para essa estrutura; (iv) fazer levantamento dessas variações na língua; (v) identificar suas vantagens seletivas. O mesmo Steels fez alguns estudos de simulação (STEELS apud GONG; COUPÉ, 2011) para medir complexidade em sintaxe e semântica. Preliminarmente tais estudos sugerem duas hipóteses: (i) a língua apresenta complexidade em sua estrutura por conta de suas estratégias comunicativas próprias; (ii) a emergência da complexidade linguística é fruto da própria organização do sistema linguístico, e da necessidade de auto-organização das culturas.

No mesmo Workshop foram ainda apresentadas propostas de Lucia Loureiro-Porto (apud GONG; COUPÉ, 2011) que trabalha na interface entre linguagem e sociedade. Essa linguista fez testes que mostram, por exemplo, que o bilinguismo acelera a morte de uma língua. Ela aposta mais na volatilidade da língua do que no seu prestígio social.

Fermin Moscoso del Prado (apud GONG; COUPÉ, 2011) procura mostrar que 
os crioulos e mesmo os pidgins não são tão simples como parecem. Aliás, nessa linha, os importantes trabalhos de John McWorther (2007), que dedicados a observar crioulos, propõem aparatos robustos para medir a complexidade de línguas em contato e em formação.

Além desses trabalhos, Newmeyer e Preston (2014) apresentam propostas de medir complexidade na Gramática, mas de modo diferente aos estudos propostos pela Gramática Gerativa. Segundo os autores, se assumirmos que as línguas são biologicamente determinadas, logo teremos que assumir que são todas igualmente complexas, ou que são igualmente simples, o que implicaria em dizer que não há nenhuma diferença substancial entre elas. Nesse sentido, todos os esforços sobre a Complexidade Linguística estariam fadados ao fracasso. Para eles, a definição de que todas as línguas são igualmente complexas só é questão pacífica entre linguistas depois dos anos 1950, mais precisamente com a publicação do artigo de Rulon Wells (1954 apud NEWMEYER; PRESTON, 2014). E ainda, para os mesmos Newmeyer e Preston (2014), a noção de "compensar complexidade" linguística teria vindo já de Whitney, em 1875.

Embora haja todas essas propostas, dois nomes se destacam sobremaneira dentro dos estudos sobre Complexidade Linguística. Guy Deutscher (2014), que tem produzido trabalhos relevantes nesse sentido, os quais privilegiam desde a sintaxe até a origem das línguas, como é o caso de O Desenrolar da Linguagem, traduzido para o Português em 2014. O outro é o já citado John McWorther, que apresenta pelo menos dois trabalhos importantes sobre crioulos, pidgins e línguas de contato que envolvem estudos sobre complexidade linguística. McWorther (2007) tem mostrado eficientemente como os estudos sobre Complexidade Linguística podem ser aplicados de maneira bastante produtiva.

Conforme vimos até agora, o campo de estudos Complexidade Linguística não se apresenta ainda como um programa coeso de pesquisa, embora haja publicações e congressos há mais de uma década sobre o assunto.

De todo modo, a Complexidade Linguística, dadas essas muitas publicações, congressos e debates, mostra-se bastante promissora em suas propostas e assunções. É verdade, no entanto, que muitos problemas que o campo propõe e enfrenta ainda estão sem resposta. Por exemplo: (i) há línguas com categorias gramaticais mais complexas que outras? Se sim, (ii) quais seriam essas categorias, e (iii) sob quais perspectivas deve-se analisá-las? (iv) Há vantagem em uma língua ser mais ou menos complexa? (v) Há critérios de "valoração" nessas ponderações? (vi) Se uma língua ganha ou perde complexidade num aspecto, é compensado em outro? Por quê? 
Seja como for, algumas reflexões já se colocam de maneira bastante importante. Deutscher (2009), por exemplo, diz que:

O nível mínimo de complexidade necessário para a comunicação está muito abaixo do limite máximo de complexidade que o cérebro humano pode suportar, e uma vez que existem processos que tanto aumentam a complexidade como o diminuem, não há, a priori, razão pela qual todas as línguas devam convergir para até aproximadamente o mesmo ponto de complexidade geral ${ }^{3}$ (in SAMPSON; GIL; TRUDGILL, 2009, p. 246).

O mesmo Deutscher (2009) lembra que, em se tratando de complexidade linguística, o estudo meramente da estrutura ou meramente dos contextos linguísticos em separado não dão conta dos fenômenos envolvidos. Nesse sentido, tanto estudos advindos de fenômenos extralinguísticos (HAWKINS, 2014), quanto estudos estruturais (CULICOVER, 2013; MIESTAMO; SINNEMÄKI; KARLSSON, 2008; SAMPSON, GIL E TRUDGILL, 2009) são essenciais para o entendimento sobre a Complexidade Linguística.

\subsection{Aplicações dos estudos de Complexidade}

Ao longo desta apresentação vimos como os estudos sobre complexidade linguística podem ser aplicados nas mais diversas áreas recobertas pela Linguística. Os trabalhos mais profícuos, até agora, são os da Aquisição de Línguas, Tipologia e os dos estudos sobre Crioulos / Pidgins. De todo modo, tais estudos parecem surgir oportunamente para dar conta de uma defasagem histórica: até então, tratar Complexidade Linguística era de fato um tabu entre os estudiosos da linguagem; e ao contrário, estamos vendo um promissor campo de estudos nascer diante dos nossos olhos.

Há discordâncias, há ressalvas e, sobretudo, há muitos ajustes a serem realizados. Conforme lembra Deutscher (apud SAMPSON; GIL; TRUDGILL, 2009), não podemos definir Complexidade Linguística em termos gerais, isso porque não existe, via de regra, a língua em termos gerais, mas apenas vistas como "partes de um sistema”. Ou seja, ainda que haja um furor diante desse novo campo de estudos, alguns preceitos tradicionais não podem ser perdidos de vista.

No limite, estudar Complexidade Linguística, além de desfazer um antigo tabu, prova também que precisamos rever critérios que, ainda hoje, perduram nos estudos sobre a linguagem, critérios que se colocam entre a realidade linguística e os valores estilísticos

3 The minimum level of complexity required for communication is far below the maximum limit of complexity the human brain can handle, and as there are processes which both increase complexity and decrease it, there is no a priori reason why all languages should converge on even roughly the same point for overall complexity (SAMPSON; GIL; TRUDGILL, 2012). 
que dela podem ser explorados. Novamente citando Deutscher (apud SAMPSON; GIL; TRUDGILL, 2009): "um relógio feito com peças de ouro, funciona da mesma maneira que um relógio feito de metal” (2009, p. 256).

\section{Aquisição de L2 tendo complexidade como parâmetro de trabalho}

\subsection{Método CAF e a Complexidade a serviço da SLA}

Um dos principais objetivos dos estudos sobre aquisição de L2, ao menos no domínio da Linguística Aplicada, é a proficiência do falante estrangeiro, em que alguns parâmetros para atingir tal objetivo são necessários. Desde os anos de 1970, há um parâmetro que vem sendo melhor desenvolvido, e que se passou a chamar de CAF (Complexity, Accuracy and Fluency). Justamente, na SLA tal parâmetro serve para "medir" a proficiência de um falante frente ao desafio de aprender - ou adquirir - a L2. Dizemos que tal "medida" vem se desenvolvendo nos últimos anos precisamente porque vem aliando-se aos modernos estudos da chamada Complexidade Linguística (SZMRECSANYI; KORTMANN, 2012; e HOUSEN; KUIKEN; VEDDER, 2012).

Housen, Kuiken e Vedder (2012) propõem as seguintes questões: o que faz com que um falante de L2 seja proficiente numa língua estrangeira? De que maneira, para um falante de L2, se atinge proficiência de modo mais eficaz? Dessa forma, novamente, percebe-se que a "proficiência" em L2 é essencial para a SLA.

Nesse sentido, para tentar sanar as questões acima propostas, chegou-se à conclusão de que a proficiência não depende apenas de um aspecto linguístico - o qual seja, o ensino ou o aprendizado individual do falante de L2 - mas que tal característica é de natureza multicomponencial. Os mesmos autores acreditam que tal empresa seja melhor aproveitada em observância a três aspectos inerentes à língua em seu estado de aquisição: complexidade, precisão e fluência, ou CAF na sigla inglesa.

Dito de outra forma, o método CAF presta-se a conferir se houve aquisição completa de L2, e isso se torna possível "medindo" de algum modo sua complexidade:

Nos últimos anos, a tríade CAF surgiu como um complemento notável a outros modelos de proficiência estabelecidos, tais como o modelo de quatro habilidades tradicionais e o os modelos sociolinguísticos e cognitivos de proficiência de L2 (e.g. Bachman 1990; Bialystok 1994; Canale \& Swain 1980). (HOUSEN; KUIKEN; VEDDER, 2012, p. 3). ${ }^{4}$

\footnotetext{
${ }^{4}$ In recent years the CAF triad has emerged as a notable complement to other established proficiency models such as the traditional four-skills model and sociolinguistic and cognitive models of L2 proficiency (e.g. Bachman 1990; Bialystok 1994; Canale \& Swain 1980) (HOUSEN; KUIKEN; VEDDER, 2012, p. 3)
} 
Ainda, o método CAF procura suas premissas em dados qualitativos, na medida em que sua pretensão é o ensino e aquisição de L 2 de modo pleno e satisfatório, e por mais que tal método tenha sido bastante disseminado, há críticas à sua validade, sobretudo a científica.

\subsection{Outros métodos disponíveis}

Segundo SZMRECSANYI; KORTMANN (2012), mesmo dentro da SLA, há várias formas de se enxergar e mesmo de medir Complexidade Linguística, os quais sumariamente apresentaremos em seguida: Complexidade Fonológica (NICHOLS, 2009; SHOSTED, 2006 apud SZMRECSANYI; KORTMANN, 2012): mede-se aí o tamanho do inventário fonológico, a incidência de fonemas marcados, a distinção total de fonemas suprassegmentais, as restrições fonotáticas e, finalmente, a complexidade máxima de encontros consonantais. Complexidade Morfológica (DAMMEL; KÜSCHNER, 2008 apud SZMRECSANYI; KORTMANN, 2012): segundo os autores, deve-se observar aqui: o escopo da morfologia flexional em uma dada língua ou variedade. Especificamente, o que é alomorfia e quais são os processos morfofonêmicos induzidos por "fatores de perturbação" (BRAUNMÜLLER, 1990 apud SZMRECSANYI; KORTMANN, 2012), e não apenas na morfologia flexional. Complexidade Sintática (GIVÓN, 2009, KARLSSON, 2009 apud SZMRECSANYI; KORTMANN, 2012): quantas regras existem na sintaxe de uma língua (mote: quanto mais, mais complexa, parafraseando MCWORTHER, 2007), e o que e quais são os níveis de cláusulas subordinadas e encaixadas (ou seja, a recursividade) permitidos por uma dada língua em questão. Observe-se que o grau de incorporação, aliás, é também, de longe, a métrica mais popular de complexidade em pesquisa SLA. Complexidade Semântica e Lexical: Complexidade lexical métrica, ou para avaliar inventário léxico adquirido pela SLA. Complexidade Pragmática: Segundo Bisang (2009 apud SZMRECSANYI ; KORTMANN, 2012)), “complexidade escondida”. Qual a interferência da pragmática de uma língua por parte dos aprendizes desta para adquiri-la?

Em suma, nenhuma dessas técnicas se faz totalmente eficiente se usadas completamente isoladas em apenas um aspecto da língua. Da mesma forma, não há viabilidade ou proveito em se medir complexidade segundo esses critérios em apenas uma língua ou mesmo em algumas poucas línguas. Dessa forma, seriam bem aplicados tais critérios de medição de complexidade se comparados a várias e diversas línguas:

Shosted (2006), por exemplo, investiga complexidade morfológica e fonológica em uma amostra de 34 línguas e descobre que não existe uma 
relação significante, e não existe troca entre complexidade fonológica e morfológica; Nishols (2009) também explora as complexidades locais numa ampla variedade de línguas e não consegue apontar uma troca. Fenk-Oczlon \& Fenk (2008) diagnosticam "efeitos de equilíbrio" entre complexidades locais, mas não na medida em que o dogma equicomplexional ${ }^{5}$ poderia ser assumido em todas as realidades e em todas as circunstâncias. Gil (2008) argumenta que isolar as línguas não mostra necessariamente que há uma simplificação morfológica com maior complexidade em outros domínios. (SZEMRECSANYI; KORTMANN, 2012 , p. 3$)^{6}$

$\mathrm{Na}$ introdução do livro que esses autores organizaram (SZEMRECSANYI; KORTMANN, 2012), em sua revisão bibliográfica, apontam diversos teóricos que lidam com Complexidade Linguística. Entre estes, citam estudos feitos sobre o assunto, e nesses estudos, dados impressionantes comprovam, por exemplo, que algumas línguas são menos complexas que outras e, nesse sentido, não há compensações (SHOSTED, 2006; GIL, 2008; NICHOLS, 2009 apud SZMRECSANYI; KORTMANN, 2012)). Ainda, tais estudos atestam preliminarmente que línguas de comunidades mais isoladas tendem a maior complexidade estrutural, e menor complexidade vocabular.

Szmrecsanyi e Kortmann (2012) ainda citam mais duas noções que são importantes para SLA, a Complexidade de Redundância Induzida, que revela, por exemplo, os graus de dificuldade de um falante de L2 ao se deparar com uma língua que marca de maneira redundante um sintagma nominal, por exemplo, caso do português padrão na marcação do número. Nesse sentido, Dahl (2004) diz que a redundância garante a fidelidade da informação a ser veiculada pela língua. A Complexidade de Irregularidade Reduzida, utilizada por McWhorter (2007), atesta que línguas que possuem o verbo ser com paradigma flexional irregular tendem a ser mais complexas, portanto, mais difíceis de se adquirir, a princípio.

Szmrecsanyi e Kortmann (2012) ainda concordam com McWhorter (2007) e com Dahl (2004) ao afirmarem que uma língua jovem não pode ser mais complexa que uma

\footnotetext{
5 "Dogma equicomplexional” é um termo utilizado por Gil (2008) para esclarecer a antiga noção, ponto pacífico entre quase todos os linguistas, de que há compensações nos sistemas linguísticos, fazendo com que a complexidade linguística se equipare. No entanto, isso é um mito, como estamos tentando mostrar aqui. (SZMRECSANYI; KORTMANN, 2012).

${ }^{6}$ Shosted (2006), for example, investigates morphological and phonological complexity in a sample of 34 languages and finds that there is no significant correlation, and no trade-off, between morphological and phonological complexity scores; Nichols (2009) likewise explores local complexities in a wide range of languages and fails to obtain a trade-off. Fenk-Oczlon and Fenk (2008: 63) do diagnose "balancing effects" between local complexities, but not to the extent that the equicomplexity dogma could be assumed to hold true under all circumstances. Gil (2008) argues that isolating languages do not necessarily compensate for simpler morphology with more complexity in other domains (SZMRECSANYI; KORTMANN, 2012. P. $3)$.
} 
língua antiga, pois não tem os ornamentos de uma língua de idade mais avançada. Ainda, concordam com Trudgill (apud SAMPSON; GIL; TRUDGILL, 2009) quando este afirma que um adulto aprendendo uma L2 obviamente acarretará em simplificação linguística, isso porque ele tende a suprimir redundâncias e irregularidades, além de aumentar a transparência da língua.

Nesse sentido, Dahl (2004) é incisivo: redundâncias e irregularidades são ornamentos linguísticos, características que apenas surgem com a "maturação" de uma língua. Assim, uma língua jovem - digamos um crioulo ou uma língua de contato, leia-se L2 não tem tais ornamentos. Note-se que isso afeta diretamente a aquisição de L2. Dito de outra forma, é o falante de L2 que promove tal mudança, ou melhor, que deixa de lado tais ornamentos em nome da simplificação exigida pela mera comunicabilidade em língua estrangeira.

Esses autores também mencionam um método de avaliação de complexidade para SLA chamado de Método Freiburg. Tal método procura aliar noções metodológicas e interpretação de dados de parentescos entre várias línguas. Assim, de acordo com Kortmann (apud SZMRECSANYI; KORTMANN, 2012)) visa: (i) elucidar padrões de complexidade em larga escala entre as línguas do mundo, e (ii) desenvolver uma métrica necessária para julgar os diferentes graus de complexidade. Um dos primeiros trabalhos utilizando esta técnica (KORTMANN; SZMRECSANYI, 2009; SZMRECSANYI; KORTMANN, 2009c apud SZMRECSANYI; KORTMANN, 2012) revelou que existem 46 variedades de inglês, dentre elas 11 como L2, 15 de crioulos emergentes de base inglesa. Ainda segundo a proposta dos autores, a Regra de Complexidade Ornamental consiste em avaliar a incidência relativa no estoque de uma variedade de características que adicionam contrastes, distinções ou assimetrias sem fornecer um bônus comunicativo ou funcional à língua (MCWORTHER, 2007). Um exemplo disso é que uma língua pode ou não atribuir o par de pronome pessoal 'ele'/'ela' a entidades inanimadas.

A chamada Regra da Simplicidade: explica como podem simplificar a língua num, digamos, contato entre falantes. Por exemplo, pode acontecer a perda de pronome reflexivo. Note-se que isso vem ocorrendo no Português Brasileiro (PB) atualmente, notadamente na variedade mineira, e é uma tendência marcante no PB do resto do país. Nessa esteira, surge o conceito de Simplicidade na aquisição de L2: “[...] como uma métrica de complexidade relativa, esta medida estabelece a incidência relativa no inventário de características de uma variedade que a pesquisa de SLA mostrou recorrer em variedades de 
interlíngua [...]” (SZMRECSANYI; KORTMANN; 2012, p. 9). ${ }^{7}$ Por exemplo: falantes de L2 tendem a não usar marcadores de tempo verbal ou a fazer a regularização de verbos irregulares. Dadas tais distinções teóricas, a pesquisa acima mencionada nas variedades do inglês, atestou que o inglês como L1 (primeira língua ou língua materna) tende a ser mais complexa, ou seja, tem mais "ornamentos" que suas cognatas: crioulos do inglês e, em menos incidência, de inglês como L2, são variedades atestadas como menos complexas.

Outro importante estudo na área de complexidade aplicada à SLA é o trabalho de Hong Han e Wai Man (apud HOUSEN; KUIKEN, 2012). Nesta obra, os autores estão procurando parâmetros para definir o que eles chamam de "complexidade aquisicional", buscando elucidar a complexidade no domínio da SLA. Dizem ainda que complexidade é um conceito relativo. Eles abordam um conceito bastante intrigante, a Complexidade do Desenvolvimento. Tal noção serve de critério para medir a proficiência de falantes L2 dada sua complexidade, a saber: (i) tamanho médio de palavras utilizadas por frase/sentença; (ii) quantidade de sentenças coordenadas; (iii) quantidade de sentenças subordinadas. Para Ortega (2003 apud HONG HAN; WAI MAN, 2012), quanto mais complexo, mais desenvolvida é a performance do falante. No entanto, não necessariamente melhor. Ainda de acordo com Ortega (2003 apud HONG HAN; WAI MAN, 2012), o desenvolvimento sintático para falantes de L2 significa que as formas linguísticas estão mais apropriadas para a comunicação. Dessa forma, por si só, medidas de complexidade sintática não são suficientes para provar aquisição plena. Mas o autor vai além: para ele, nenhuma medida (cognitiva, psicológica, linguística etc.), por si só, é totalmente suficiente para medir complexidade ou desenvolvimento de maneira satisfatória.

Os autores ainda mencionam outras noções bastante importantes para os estudos da complexidade em L2, tal como o da Complexidade Aquisicional, que, segundo eles, consistem nos seis seguintes aspectos: (i) O que é adquirível (de um modo complexo) por um falante ou grupo de falantes, pode não ser para outro. Complexidade de Aquisição não pode ser medida nos mesmos parâmetros que Complexidade Linguística, quais sejam: fatores externos, universais, dentre outros; (ii) A Complexidade de Aquisição é estática, enquanto que Complexidade de Desenvolvimento, não; (iii) Complexidade de Aquisição é o mesmo que aquisição de forma e função; (iv) Complexidade de Aquisição é uma função da interação estabilizada de contingências exógenas e endógenas. Dessa forma,

\footnotetext{
7 "[...] as a relative complexity metric, this measure establishes the relative incidence in a variety's inventory of features that SLA research has shown to recur in interlanguage varieties [...]"(SZMRECSANYI; KORTMANN, 2012, p. 9)
} 
um adequado estudo para avaliar a proficiência dos falantes L2 só ocorre se tal avaliação está ligada a dados elementos, tal como o relacionamento entre L1 e língua-alvo; (v) Evidências da complexidade do desenvolvimento (do Inglês, Developmental Complexity) podem, a princípio, ser coletadas em qualquer estágio do desenvolvimento. No entanto, o ponto de partida para localizar incidência de complexidade de aquisição só pode ser na amostragem de alunos que foram aprendendo na fase exógena e em condições endogenamente favoráveis, como a experiência ampliada e sustentada com a metalinguagem (por meio de livros didáticos, por exemplo). Evidências de qualquer dificuldade na aquisição da L2 podem ser usadas para fazer inferências sobre a complexidade de aquisição; (vi) Complexidade de aquisição pode ser medida ao longo do tempo, embora isso não precise ser necessariamente feito (HONG HAN; WAI MAN, 2012.).

Em seguida, os mesmos autores relacionam Complexidade de Aquisição com Dificuldade de Aprendizado, ressalvando que são noções distintas, amparados por Miestamo, Sinnemäkki e Karlsson (2008), Dahl (2004), Collins (2009 apud HONG HAN; WAI MAN, 2012) e Krashen (1982 apud HONG HAN; WAI MAN, 2012). Para Hong Han e Wai Man (2012) é mais produtivo na SLA avaliar Dificuldade de Aprendizado, na qual destacam-se as seguintes observações pertinentes: (i) A frequência com que um traço ocorre no input; (ii) Saliência: na medida em que a funcionalidade é perceptível no input; (iii) Valor funcional: se o recurso é mapeado sobre um significado claro e distinto; (iv) Processabilidade de um traço (ELLIS, 2006, 2009 apud HONG HAN; WAI MAN, 2012).

Diferentemente dos outros autores aqui citados, Hong Han e Wai Man (2012) apresentam um estudo de caso. Nesse estudo, eles observaram um professor chinês que há 15 anos lecionava inglês; assim, seria supostamente proficiente. Nas aulas - ou seja, num discurso falado, controlado - o professor sempre utilizava uma estrutura nas sentenças inglesas, que, em português, corresponderia a "Não só... mas também”. Os autores constatam que tal estrutura também existe no chinês, utilizada de uma forma bem parecida ao inglês. Nesse sentido, seja talvez por esta razão que o professor chinês utilizava sempre tal estrutura. Dito de outra forma, o professor utilizava sempre essa estrutura porque fazia uma ponte da língua estrangeira que estava utilizando com sua língua mãe. Poderíamos citar um exemplo sentencial mais próximo de nossa realidade linguística. Informalmente, ao ver um diálogo entre dois falantes, um nativo (L1) em língua inglesa e outro brasileiro (L2) falando inglês, constatei a seguinte sentença: "He brokes the legs". ${ }^{8}$ Ao ser proferida, o falante de inglês não entendeu plenamente o que o brasileiro falou. Analogamente ao

\footnotetext{
8 "He brokes his legs" seria a sentença gramaticalmente aceita.
} 
caso do professor chinês, parece que falantes de L2 tendem a "parametrizar" ou aproximar parâmetros de sua língua nativa, "traduzindo-os" à L2.

Ainda, Hong Han e Wai Man (2012) comentam a noção de Fossilização, que é um conceito chave para SLA. Baseado em Long e Crookes (1992 apud HONG HAN; WAI MAN, 2012, p. 200), os autores tiram as seguintes premissas: (i) Unidades linguísticas não são unidades de aquisição, i.e.: unidades que são realmente processadas e adquiridas; (ii) Robinson (1996 apud HONG HAN; WAI MAN, 2012, p. 201): complexidade de aquisição é diferente de dificuldade, complexidade é externa, e dificuldade é interna. Complexidade de aquisição pode não ser difícil para certos falantes; (iii) Estruturas fossilizadas são complexas; (iv) Somente em pesquisas longitudinais pode-se provar o que é complexidade de aquisição.

Por fim, os autores definem o que seja aquisição segundo Larsen-Freeman (2001 apud HONG HAN; WAI MAN, 2012), uma relação entre forma, função e sentido, dada nesta ordem: forma > forma-sentido > forma-sentido-função ganhando, dessa forma, e nessa medida, mais complexidade. Para Sorace (apud HONG HAN; WAI MAN, 2012), a complexidade de aquisição, ainda que não seja plena, exige do falante não apenas conhecimento sintático, mas a habilidade de coordenar conhecimento sintático com outros conhecimentos. Lembrando-se da estrutura sintática retirada como exemplo do professor chinês.

\subsection{Uma Crítica à Complexidade como parâmetro de pesquisa}

Bulté e Housen (2012) são críticos do método CAF. Segundo esses autores, existem pelo menos duas vertentes distintas dos estudos da complexidade relacionadas à L2. Uma delas usa complexidade como variável independente, a CAF. A outra, como variável dependente. Nesta, a complexidade do aprendiz de L2 é medida e comparada a outras variáveis:

[...] [os] resultados inconsistentes podem, pelos menos em parte, serem explicados pela forma com que complexidade em L2 foi definida e mesmo operacionalizada. Muitos estudos de L2 que investigam 'complexidade' ou não definem o que querem dizer com esse termo ou, quando o fazem, é em termos gerais, vagos ou mesmo circulares. (BULTÉ; HOUSEN, 2012, p. 22). ${ }^{9}$

\footnotetext{
9 [...] [the] inconsistent results can at least partly be accounted for by the way in which L2 complexity has been defined and operationalised. Many L2 studies that investigate 'complexity' either do not define what they mean by this term, or when they do, they do so in general, vague or even circular terms (BULTÉ; HOUSEN, 2012, p. 22)
} 
Para esses autores, uma boa definição de complexidade para fins de SLA seria número e natureza dos componentes discretos por que a entidade linguística é constituída, bem como o número de relações entre os componentes constituídos por essa entidade. E, assim como Miestamo, Sinnemäki, Karlsson (2008) e Dahl (2004), esses autores fazem a distinção entre Complexidade Relativa e Complexidade Absoluta, praticamente segundo os mesmos parâmetros. Para Bulté e Housen (2012), complexidade relativa, ou complexidade cognitiva, refere-se à dificuldade, ou seja:

A abordagem relativa define complexidade em relação aos usuários da língua: um recurso de linguagem ou sistema de recursos que é visto como complexo se é de alguma forma cara ou onerosa aos usuários da língua e aos alunos, particularmente em termos do esforço mental ou recursos que eles têm para investir em transformação ou para internalizar tais recursos. (BULTÉ; HOUSEN, 2012, p. 35)..$^{10}$

Segundo esses autores, critérios como custo ou dificuldade ainda são bastante relativos. Nesse sentido, são difíceis de serem medidos e, portanto, difíceis de serem utilizados como critérios científicos.

Para Bulté e Housen, Complexidade Absoluta, em termos quantitativos, mede o número de componentes apresentados pelo sistema de uma dada língua. Assim, a dificuldade é uma noção mais ampla do que a complexidade inerente, que é apenas um dos fatores que podem contribuir para a aprendizagem ou dificuldade de processamento (BULTÉ; HOUSEN, 2012, p. 36). Dessa forma, não há uma relação de "um-para-um” entre complexidade e dificuldade de aprendizagem de uma língua.

Esses autores também procuram estabelecer alguns critérios para medir complexidade. Para propósitos heurísticos, dividem a Complexidade de L2 em três noções: (i) Complexidade proposicional: consiste no número de informação ou nas unidades de ideia que o falante codifica numa língua para transmitir conteúdo; (ii) Complexidade Discursivo-interativa: refere-se a mudanças e interações que os falantes participantes da interação realizam no ato da fala; (iii) Complexidade Linguística: que tem sido interpretado na literatura de L2 de duas maneiras diferentes: ou como uma propriedade dinâmica do sistema de L2 do aluno; ou como uma propriedade mais estável dos individuais nos itens linguísticos, estruturas ou regras que compõem o sistema de L2 do aluno (complexidade local ou estrutura) (BULTÉ; HOUSEN, 2012, p. 37).

${ }^{10}$ The relative approach defines complexity in relation to language users: a language feature or system of features is seen as complex if it is somehow costly or taxing for language users and learners, particularly in terms of the mental effort or resources that they have to invest in processing or internalizing the feature(s)" BULTÉ; HOUSEN, 2012, p. 35) 
Dadas essas distinções, os autores ainda postulam: Complexidade Global ou Sistêmica, que se refere ao grau de elaboração, o tamanho, a largura ou a riqueza do sistema de L2 do aluno ou 'repertório', isto é, ao número, gama, variedade ou diversidade de diferentes estruturas e itens que ele sabe ou utiliza: se ele domina uma pequena ou uma ampla gama de diferentes palavras ou diferentes estruturas gramaticais, se ele controla a totalidade ou apenas uma parte do sistema de som do L2, e assim por diante (BULTÉ; HOUSEN, 2012, p. 37).

Seguindo vários teóricos da complexidade, Bulté e Housen (2012) ainda observam mais duas distinções possíveis no nível teórico: a Complexidade Funcional e a Complexidade Formal.

Complexidade Funcional se refere ao número de sentidos e funções de uma estrutura linguística, ao grau de transparência, ou multiplicidade, do mapeamento entre forma e significado/função de um recurso linguístico. Relação forma/função/sentido, citam a marcação número/pessoa etc. em verbos em inglês. Tais autores dizem que línguas que não possuem tal marcação são mais simples, ao menos sob este aspecto.

Complexidade Formal: refere-se ao número de características, incluindo a "substância” estrutural de um traço linguístico, determinado pelo número de traços discretos de uma forma linguística (por exemplo, o passado simples vs. presente perfeito em inglês). Além disso, pode-se definir complexidade formal como o número de operações aplicadas a uma base estrutural para se chegar a uma estrutura-alvo.

Obviamente, os diferentes tipos de complexidade aqui descritos são apenas construtos teóricos: "Na realidade do uso da linguagem e da aprendizagem, várias destas construções de complexidade podem ser estreitamente interligados, o que dificulta a sua identificação e avaliação" (BULTÉ; HOUSEN, 2012, p. 38).

Esses autores ainda chamam a atenção para as contradições existentes entre teóricos para nomear os mesmos fenômenos em nomes e formas diferentes, o que prova que as classificações no que tange o que seja complexidade urgem de uma sistematização mais acurada, ou mesmo de uma normatização. Dado esse problema, sugerem três níveis de entendimento para tal abstração dos estudos sobre complexidade em L2: (i) Complexidade pode ser analisada como nível abstrato, ou seja, no nível cognitivo; (ii) observando-se o funcionamento da linguagem, ou seja, não mais no nível cognitivo da abstração; (iii) nível de medidas analíticas, ou de fatos concretos, ou seja, quantitativa. Aqui, comparam-se as amostras de diferentes línguas em diferentes níveis de observação. Em suma, os três níveis podem ser assim nomeados: teorético, observacional e operacional: 
Em um nível mais concreto, de observação de desempenho de linguagem, como exemplificado por uma amostra de uso da linguagem real, essas noções teóricas de complexidade podem ser manifestadas no comportamento da linguagem de várias maneiras e em vários níveis diferentes (por exemplo, o uso de estratégias diferentes para combinar e incorporação de cláusulas, utilizando formas verbais diferentes ou especializadas contra o vocabulário mais comum) (BULTÉ; HOUSEN, 2012, p. 39). ${ }^{11}$

Ao lado dos problemas de definição e construção (o fato de que a complexidade em pesquisa CAF carece de definições adequadas suportados pelas teorias da linguística, a cognição ou a aprendizagem de línguas), também existem problemas quanto à sua operacionalização, ou seja, como a Complexidade Linguística tem sido, e pode ser, validamente, confiável e eficientemente medida em pesquisa empírica (BULTÉ; HOUSEN, 2012, p. 57), concluem os autores.

\section{Considerações Finais}

Como pudemos notar, os estudos sobre Complexidade Linguística são bastante recentes, por isso seus critérios de pesquisas, métodos e, sobretudo, modo de medir complexidade na língua ainda parecem ser muito incipientes. Por um lado, a Complexidade Linguística vista como característica inerente às línguas é de suma importância para o entendimento de várias áreas da linguística, inclusive à SLA, conforme visto aqui. Por outro lado, talvez dada a suposta incipiência dos estudos sobre complexidade, muito do que se apregoa sobre o assunto, segundo seus defensores, parece ainda não ser devidamente aproveitável, ou parece ainda não apresentar métodos e resultados conclusivos, em especial no que tange à aquisição de L2.

No entanto, alguns resultados preliminares trouxeram avanços significativos, conforme vimos. Seja como for, o campo de estudos sobre a complexidade vem ganhando notoriedade, e junto a ele e suas contribuições, a SLA vem também ganhando mais uma ferramenta, sobretudo talvez no que tange ao ensino de línguas estrangeiras, recoberto pela Linguística Aplicada. As críticas e oposições feitas aos estudos da complexidade obviamente auxiliam para que tais estudos avancem e aperfeiçoem seus métodos de pesquisa, mas seu olhar - na contramão do tabu, até pouco tempo estabelecido - parece vir contribuindo sobremaneira, não somente para a SLA, mas para diversos campos dos estudos linguísticos.

\footnotetext{
${ }^{11}$ On a more concrete, observational level of language performance, as exemplified by a sample of actual language use, these theoretical notions of complexity can be manifested in language behaviour in various ways and on several different levels (e.g. in the use of different strategies for combining and embedding clauses, by using different verb forms or specialized versus more common vocabulary). (BULTÉ; HOUSEN, 2012, p. 39)
} 


\section{Referências}

BORGES Neto, José. Ensaios de Filosofia da Linguística. São Paulo: Parábola. 2002.

BULTÉ, Bram; HOUSEN, Alex. "Defining and Operationalising L2 complexity". In: HOUSEN, Alex; KUIKEN, Folkert; VEDDER, Ineke (Org.). Dimensions of L2 Performance and Proficiency. Amsterdam: John Benjamins. 2012.

CULICOVER, Peter W. Grammar \& Complexity - Language at Intersection of Competence and Performance. London: Oxford Press. 2013.

DAHL, Östen. The growth and maintenance of linguistic complexity. Amsterdam: John Benjamins. 2004.

DEUTSCHER, Guy. “Overall complexity: a wild goose chase?”. In SAMPSON, Geoffrey; GIL, David; TRUDGILL, Peter (Org.). Language Complexity as an Envolving Variable. New York: Oxford Press. 2009.

DEUTSCHER, Guy. O Desenrolar da Linguagem. Campinas: Mercado de Letras. 2014.

GONG, Tao; COUPÉ, Christophe. AReporton the Workshop on Complexity in Language: Developmental and Evolutionary Perspectives. Biolinguistics. 5, pp.: 370-380. 2011.

HAWKINS, John. Cross-Lingusitics Variation and Efficiency. London: Oxford. 2014.

HOUSEN, Alex; KUIKEN, Folkert; VEDDER, Ineke (Org.). Dimensions of L2 Performance and Proficiency. Amsterdam: John Benjamins. 2012.

HONG HAN, Zhao; WAI MAN, Lew. "Acquisitional Complexity - What defies complete acquisition in Second Language Acquisition”. In: HOUSEN, Alex; KUIKEN, Folkert; VEDDER, Ineke (Org.). Dimensions of L2 Performance and Proficiency. Amsterdam: John Benjamins. 2012.

KUSTERS, Wouter. Linguistic Complexity: The Influence of Social Change on Verbal Inflection. Ultrechet: LOT, 2003.

MCWORTHER, John. Language Interrupted. New York: Oxford. 2007.

MIESTAMO, Matti; SINNEMÄKI, Kaius; KARLSSON, Fred (Org.). Language Complexity: Typology, contact, change. Amsterdam: John Benjamins. 2008.

NEWMEYER, Frederick; PRESTON, Laurel (Org.). Measuring Grammatical Complexity. London: Oxford Press. 2014.

ROBINS, Robert Henry. Pequena História da Linguística. Rio de Janeiro: Ao Livro Técnico, 1979.

SAMPSON, Geoffrey; GIL, David; TRUDGILL, Peter (Org.). Language Complexity as an Envolving Variable. New York: Oxford Press. 2009.

SZMRECSANYI, Benedikt; KORTMANN, Bernd (Org.). Linguistic complexity - Second Language Acquisition, indigenization, contact. Berlin: DeGruyter. 2012. 
TRUDGILL, Peter. "Sociolinguistic Typology and Complexification". In SAMPSON, Geoffrey; GIL, David; TRUDGILL, Peter (Org.). Language Complexity as an Envolving Variable. New York: Oxford Press. 2009.

(c) 9

Data de submissão: 30/10/2017

Data de aceite: 30/05/2018 